\title{
Standing in a Garden of Forking Paths
}

\author{
Clayton Littlejohn \\ (clayton.littlejohn@kcl.ac.uk) \\ King's College London
}

\section{Introduction}

A thinker's evidence supports some of the conclusions that they've drawn but probably not all of them.' (Even the most rational thinkers have the odd irrational belief.) It supports some conclusions that they've never drawn and infinitely many that they never will. (Nobody can or should believe all the obvious consequences of the things they know.2) There are also some conclusions that aren't supported by a thinker's evidence now and never will be supported by it. (I would wager that nobody will have sufficient evidence to believe that the number of stars is even.) When there is no path that takes us from our evidence to a conclusion by means of good reasoning, it would seem there is no justification for drawing this conclusion. When a path is present, however, it seems to ensure that there is justification for what we believe even if, because of bad luck, our conclusions are mistaken.

One way to think of the normative significance of evidence is in terms of these paths of evidential support. ${ }^{3}$ The presence of a path means that in principle a thinker could reason from the evidence they have now in such a way that they would always have justification to believe the conclusions the path takes them to. On the other hand, when there is no path that takes them from their current evidence to a conclusion via

- I would like to thank Kevin McCain for extensive helpful written feedback on this paper. I would also like to thank Maria Alvarez, Bill Brewer, Christopher Cloos, Charles Cote-Bouchard, Christina Dietz, Julien Dutant, Matthew Frise, John Hawthorne, Andrew Moon, and Ram Neta for helpful conversations on these issues.

2 It should be obvious that nobody can believe the obvious consequences of what they know. If 'ought' or 'should' imply 'can', it would be wrong to say that a thinker should believe every obvious consequence of what they know. A thinker may believe whatever she sees follows from what she knows, but as I haven't seen a good case for believing that a thinker ought or should believe whatever she has adequate reason to believe.

${ }^{3}$ How should 'support' be understood? How should 'adequate support' be understood? The title was chosen because I'm interested in normative standing or status and how it is determined. I shall assume that my opponent is someone who thinks that support is something that is itself non-normative and that it potentially has a normative upshot. I won't assume much of anything about what kind of non-normative relations would have to be in place to ensure that a belief could attain some kind of positive standing. If readers are attracted to a view of support on which evidence supports by raising the probability of something and characterizes adequacy of support in terms of a degree of support that crosses a threshold, so be it. If instead they think we cannot say much of anything informative about the kind of support except to say that it is there iff something 'fits' the evidence, that should be fine, too. The support relations might be primitive but I shall assume that support, however, characterized satisfies the weak constraints outlined below. 
good reasoning, they either need to acquire new evidence or refrain from drawing this conclusion. Relations of evidential support provide us with paths that we might permissibly follow but we cannot justifiably believe anything if a path doesn't take us there from where we are now.

This is a tempting picture. It suggests that something like this principle must be true:

The Path Principle: The types of support relations that hold between a thinker's evidence and the propositions she grasps wholly determine whether there is propositional justification for believing these propositions.

The principle tells us something negative and something positive. The negative point is that there is no way to have justification to believe something without a path that takes you to that belief that's provided by supporting evidence. The positive point is that the presence of such a path is all you need for justification to draw a conclusion.

While I can understand the temptations to buy into this picture, this gives us a distorted picture of what justification is. We often speak of the available evidence as 'a justification' where we mean that it is something that we would cite in support of our belief. We also speak of 'a justification' as a kind of normative status that is like a permission or entitlement. It is something we have only when our beliefs conform to the epistemic norms or standards that govern belief. The relationship between them is messy. I do not think that there are always evidential paths that necessarily take us from where we are to beliefs that conform to these norms. The connection between following the paths of evidential support and conforming to epistemic norms is contingent. Talk of 'sufficient' evidential support obscures this because it suggests that there is something in the evidential support relations that would be sufficient to ensure that our beliefs are justified. There is not. ${ }^{5}$ Moreover, the presence of an evidential path

' Among other things, it is possible that a thinker has 'a justification' in one sense without having 'a justification' in the other because the justification the thinker has is not up to the task.

${ }^{5}$ Recall Clifford's suggestion that it is wrong to believe without sufficient evidence. What could he mean by 'sufficient'? I don't think he could have meant that a thinker has sufficient evidence for her beliefs if it isn't wrong for her to hold those beliefs. The idea had better be that there's some way of understanding what it takes for the evidential support to be sufficient that isn't cashed out in terms of what is or is not wrong to believe that accounts for the fact that some beliefs are wrongfully held and others are not. To get a fix on the relevant notion, it's helpful to start with some examples where there is all the evidential support we could hope to have (e.g., the evidential support that is present in paradigmatic cases of knowledge) and then think about ways of understanding how this kind of support could be present or absent in other cases (e.g., cases where a thinker would seem to have all the same evidence). The sufficiency of support should be common when we're dealing with thinkers who have identical evidence or evidence that has all the same kinds of support relations. The argument against the Sufficiency Thesis is an argument that there is no notion of 
is not always necessary for justification. There are situations where we can justifiably add a belief to our belief set even though there was no path that led us there. There is both more and less to justification than evidential support.

My target in this paper is the evidentialist view that is presupposed by the Path Principle. It is the view that says that facts about what a thinker has justification to believe (i.e., a right or permission to believe) are wholly determined by facts about a thinker's evidence (e.g., what is included in her evidence, what support relations hold between her evidence and the propositions that she grasps). I've argued previously that justification does not supervene upon the evidence. ${ }^{\text {The }}$ Thennection between a thinker's justification or her reasons and the resultant normative status of her beliefs is contingent, not necessary. In this paper, I shall provide additional arguments against this supervenience thesis and an argument against a stronger determination thesis, an argument that shows that the Path Principle would be false even if a kind of supervenience thesis were true.

\section{Setting the Stage}

Let's say that 'evidentialism' picks out a theory of a kind of normative standing: propositional justification. I take propositional justification to be a kind of normative standing because when a thinker has it, it is acceptable, proper, or permitted for the thinker to believe some proposition. Our discussion will focus on the justification of full belief. This is the kind of belief that is required for knowledge and is presupposed by propositionally specified reasons explanations of the agent's actions and affective responses. If readers wish to draw any lessons about partial belief, they will need to import assumptions about full and partial belief that are not presupposed in this discussion. In short, evidentialism is a theory about the justification of this kind of attitude.

Evidentialism is the view that a thinker's evidence (at a time) wholly determines whether there is sufficient justification for this thinker to believe $\mathrm{p}$ (at that time). ${ }^{\text {. To }}$ allow for various kinds of defeat, we should be open to the idea that the thinker's total evidence or some large portion of it determines whether there is sufficient justification for the thinker to believe a proposition (i.e, the justification of a belief turns on more than the thinker's justification for holding that belief even on the evidentialist view). While evidentialism implies that a certain supervenience thesis is true, the thesis is more interesting than any supervenience thesis. Supervenience is cheap. ${ }^{8}$ It does not imply that any interesting kind of dependence or determination thesis holds. All the necessary truths supervene upon the contingent truths about cheese and clocks, but nobody thinks that this tells us anything about metaphysical priority. It also does not

sufficiency that suits the evidentialist's needs (i.e., is a non-epistemic or non-normative property that is sufficient for some epistemic or normative property).

'See my (2012), especially chapter 6.

? This fits Conee and Feldman's (2004) characterization. See also McCain (2014).

- Comesana (2005) reminds us of this fact and turns it into an argument for externalism. 
imply that any interesting kinds of patterns of generalizations would hold. Even if justification supervened upon a thinker's evidence it could be that, say, two thinkers with very similar bodies of evidence could differ radically in terms of what they would have justification to believe. ${ }^{9}$ Evidentialism isn't supposed to be cheap in these ways. It tells us that some non-epistemic facts (i.e., facts about evidence and evidential support) are prior to some epistemic facts (i.e., facts about propositional justification) and it implies that interesting patterns hold.

The Path Principle is supposed to capture three important dimensions of evidentialism. First, it tells us that there is a decisive reason not to believe when there is no evidential path that takes a thinker from where they are now to a new belief:

The Dependence Thesis: There is no situation in which it is appropriate for a thinker to believe $\mathrm{p}$ where the thinker does not possess evidence that provides the right support for believing $\mathrm{p}^{10}$

Second, it tells us that certain non-epistemic evidential support relations are all that matter for propositional justification:

The Sufficiency Thesis: There is no situation in which a thinker's evidence provides the right support for believing $p$ if there is a situation where this type of evidential support relation fails to provide sufficient support for believing a suitable counterpart of $\mathrm{p}$.

If, say, Agnes' evidence differs from Agatha's only at the level of sense (e.g., Agnes thinks of Venus as Hesperus and Agatha thinks of Venus as Phosphorus), they should have the same paths open to them since the kind of support that Agnes' evidence

' It could be that Agnes' evidence supports her belief that Hesperus shines and that this belief of hers is justified. It could be that Agatha's evidence differs from Agnes' only in that Agatha knows that two is the smallest prime. If there is just this difference in their evidence, the supervenience of justification on evidence could hold and yet Agatha could fail to have justification to believe that Hesperus shines. It would seem that such differences shouldn't have any bearing on what justification Agatha has. It certainly doesn't seem to have any bearing on what her evidence supports, how much support her evidence provides, etc. Thus, there had better be more to evidentialism than a supervenience thesis that allows for these kinds of differences.

${ }^{10}$ There is one wrinkle to consider. As I understand it, the Dependence Thesis tells us that if a thinker justifiably believes $p$, there is adequate evidence that supports the thinker's belief in $p$. Does this mean that there is something that is evidence that the thinker has that supports the thinker's belief in $p$ ? That is unclear. Suppose the thinker has nothing in her body of evidence. Some would say that the thinker's evidence (which includes no pieces of evidence) could still provide maximum support for a logical truth. I shall assume, contrary to this, that a thinker cannot have adequate evidence for believing $p$ unless there is something that is a piece of evidence that supports $p$ that could figure in some kind of recognizably good reasoning that leads to this conclusion. 
provides her her beliefs about Hesperus are just the kind of support that Agatha's evidence provides for her beliefs about Phosphorus."

Third, the Path Principle reminds us that the order of dependence runs from evidential support to justification:

The Determination Thesis: The propriety or impropriety of believing $\mathrm{p}$ is always determined by something more basic: the evidential support relations that hold between this content and the thinker's evidence.

This rules out views on which we'd say that there's a path open to Agnes because she's in a position to know or justifiably believe $\mathrm{p}$. The evidentialist thinks that she's in a position to justifiably believe something because of the presence of a path of suitable evidential support. Notice that these theses are neutral on how evidential support should be understood, provided that the support relation is characterizable in terms that don't make essential use of normative concepts from epistemology (e.g., rationality, responsibility, justification, or knowledge).

We will look at two problems for the Path Principle. The first problem has to do with the Dependence Thesis. However we understand evidence and its possession, there are some cases of justification without evidential support. The second problem has to do with the Sufficiency Thesis. Even when there is evidence that supports a proposition that a thinker justifiably believes, that type of support might hold in other cases and fail to justify a thinker's beliefs.

\section{The Dependence Thesis}

Cases of non-inferential belief cause trouble for the Dependence Thesis. To see why, let's consider an argument against the Dependence Thesis:

P1. There is some non-inferential knowledge.

P2. Non-inferential knowledge is either evidentially based or it is not.

P3. Non-inferential knowledge is not evidentially based.

C1. Thus, some knowledge is not evidentially based.

P4. Whatever we know we have justification to believe.

C2. Thus, there is justification that is not evidentially based.

Foundationalists accept (P1) unless they accept a virulent form of skepticism that denies the possibility of all knowledge. Evidentialists should spot us the weak foundationalist and anti-skeptical assumptions needed for (P1). The main point of contention is not (P4). Remember that the relevant notion of justification is a normative one. Few would defend evidentialism by arguing that the relevant cases are cases of knowledge where the thinker shouldn't hold the belief in question. The contentious premise is (P3). If this premise is true, the argument is sound.

" Clearly it matters that the relations among their different thoughts are sufficiently similar. If we don't hold those fixed, one thinker could infer surprising empirical truths from tautologies. 
Because our evidence is our knowledge, (P3) is true. Because non-inferential knowledge is possible, it's possible for a thinker who doesn't have any evidential basis for believing $\mathrm{p}$ to come to know $\mathrm{p}$. She would therein come to have a justified belief in $p$ without having had to have an evidential path that could take them from where they were before believing $p$ to where they are now..$^{2}$ As a consequence of coming to know $p$, the subject could acquire evidence that entails that $p$ : the fact that $p$. This fact, however, is not the evidential basis that supports the belief. The presence of this evidential basis is a consequence of coming to know and coming to have a new justified belief, not the means by which it is possible to attain the relevant belief or for that belief to attain its epistemic status.

If $\mathrm{E}=\mathrm{K}$ is correct and non-inferential knowledge is possible, it should be possible to construct counterexamples to the Dependence Thesis. ${ }^{3}$ We might suppose that at $t$, Agnes and Agatha are evidential duplicates. Agnes and Agatha open their eyes and look out their respective windows. Agnes sees rain clouds. Agatha sees blue skies. As a consequence, Agnes is in a position to know that it is cloudy and that the skies aren't blue. Thus, she has justification to believe that it is cloudy and does not have justification to believe that the skies are blue. Agatha, however, is in a position to know that the sky is blue. She has justification to believe this and does not have justification to believe that it is cloudy. ${ }^{14}$ This difference is not a consequence of the evidence they had at $\mathrm{t}$ prior to coming to believe anything about the weather.

Because they have the same evidence at $t$, they should have the same evidential paths at t. However, at $t^{\prime}$, Agnes justifiably believes something that Agatha could not

${ }_{12}$ Could the evidentialist say that there are cases of knowledge or justified belief without evidential grounding? Perhaps, but they would then be committed to an absurdly permissive view. If we thought that someone who had no evidence for $p$ or for $\sim p$ could nevertheless justifiably believe $p$, the Sufficiency Thesis would tell us that there would be a general permission for those who lacked evidence to believe what they had no evidence to believe. (Why? Because we would have admitted that the evidential support relation that holds between evidence that provides no support for a belief is sufficient to justify that belief. That, in turn, would generalize across similar cases.)

${ }^{13}$ These cases are also challenges to uniqueness since the differences in what Agnes and Agatha have justification to believe would show that certain uniqueness theses are false. Uniqueness tells us that Agnes and Agatha should have justification to believe the same things if their evidence is the same, but the example shows that one has justification to believe something that the other thinker should not believe. On my view, we should think of being in a position to justifiably believe as something like being in a position to know--something that can be sensitive to evidence but not something that supervenes upon the thinker's evidence. For a defense of $\mathrm{E}=\mathrm{K}$, see Williamson (2000).

${ }^{14}$ Remember that $\mathrm{E}=\mathrm{K}$ tells us that the differences in evidential pathways that emerge will emerge as a result of coming to know different things. They are not the means by which there are interesting differences in what these thinkers are permitted to believe in light of their experiences if their experiences do not constitutively involve belief. (Even if they did constitutively involve belief, such beliefs would then be counterexamples to the Path Principle since they would not be evidentially based.) 
justifiably believe (and vice versa). If what Agnes knew at $t$ constituted an adequate evidential path that supported her beliefs at $t$ ', it should have given a path to Agatha, too. Either the evidentialist will give them too few paths (i.e., they'll say that neither Agnes nor Agatha could both justifiably believe that it was cloudy or that it was sunny) or too many paths (i.e., they'll say that neither could have any justified beliefs about the weather). Thus, we can use $\mathrm{E}=\mathrm{K}$ to show that (P3) must be true.

Obviously this argument will not persuade everyone. $\mathrm{E}=\mathrm{K}$ is a contentious thesis. I don't offer this argument because I think it will show the evidentialists the error of their ways. I offer it for two reasons. The first is that it brings out one of the ways that a commitment to the Dependence Thesis can force us to take on commitments we would prefer not to. Some evidentialists say that the view is obvious or that its core commitments are relatively unproblematic. I don't see how they can be obvious or obviously unproblematic if combining them with independently motivated epistemological views leads to unpalatable consequences. The second is that a perfectly natural way to test the Dependence Thesis is by embedding it in a framework of independently motivated claims to consider its consequences. If the consequences are problematic, we have to wonder whether the source of the problem is the Dependence Thesis or something else. If we combine the thesis with any propositional view of evidence on which possession of propositionally specified evidence requires belief in the proposition, we get the result that non-inferential justification and knowledge are impossible. I think this highlights a potentially serious problem with the thesis. We have good reason to think that evidence is propositionally specified and to think that the possession of such evidence requires belief.

Here is why $\mathrm{E}=\mathrm{K}$ causes trouble for the Dependence Thesis. To accommodate the Dependence Thesis, the evidentialist offers an account of justification that contains three distinct parts:

Target: the state of the world (understood broadly) that we aim to represent accurately.

Attempt: the propositional attitude about this state that can be assessed for accuracy and evaluated epistemically.

Support: something distinct from both the target and the attempt that provides rational support for the attempts by virtue of being evidence of the relevant target states. ${ }^{16}$

${ }_{15}$ This has to be understood broadly enough that it covers every potential object of thought. Thus, it includes the external world and everything internal to the mind that we can form beliefs about.

${ }^{16}$ There are some important ground rules that we need to remember as the discussion proceeds. First, little if anything of interest about the kind of support we have follows from facts about targets. Similarly, the presence of support implies little if anything about what the targets are like. Moreover, these three types of item should be understood as distinct existences. Your attempt to settle the question whether $p$ is not support for that attempt and it is not the target. (If there are special cases where this 
If the only support that we had for our beliefs came from the things that we knew, we couldn't have support for our prospective non-inferential beliefs because the possession of such beliefs would be necessary for the possession of the relevant support. To formulate a view that accommodates the Dependence Thesis we need an account of support on which the possession of the support for some attempt (e.g., Agnes' belief about the weather) does not require the attempt itself. $\mathrm{E}=\mathrm{K}$ rules this out.

The literature is filled with alternative accounts of what constitutes a thinker's support (e.g., facts that the thinker knows or believes, propositions that are the contents of the thinker's mental states, mental states or events, etc.). This was just an opening gambit. Naturally someone who is attracted to the Dependence Thesis will want to offer an alternative account of support and its possession. Crucially, they will want an account on which the possession of the support we have for our non-inferential knowledge of $p$ does not require the belief that $p .^{.7}$ There are two very different models of non-inferential support in the literature. On the first, having support is really just a matter of having some kind of propositional or representational state of mind or mental event. ${ }^{18}$ The support might be the state itself or the content of the state, but the account involves two features. First, the support plays the support role it does, in part, because of the relationship between the content of the attempt and the content of the support. Second, the thinker must occupy the non-doxastic state or undergo the relevant mental event to have this support but the thinker need not be aware of the state or event for it to provide support. We'll call this the 'occupational' view of support because the thinker has the support by being in some state or undergoing some experience. ${ }^{19}$ On the second approach, the support is something that the thinker accesses or is aware of in some way. ${ }^{20}$ The support (and the possession condition for it) would not need to have a

breaks down, we have to see whether the exception to the general pattern is something that helps or harms the evidentialist cause.)

${ }^{17}$ If the possession of the support required the attempt in question, there would be no evidential path that would permit the thinker to make the attempt in question.

${ }^{18}$ For a defense of the statist view on which the support consists of mental states with appropriate contents, see Conee and Feldman (2008), Gibbons (2014), McCain (2014), and Mitova (forthcoming). For a defense of the propositionalist view on which the support consists of the propositional contents of these states, see Fantl and McGrath (2009). Neta (2008) makes a convincing case for the view that evidence is specified propositionally and not in terms of mental states or events.

${ }_{19}$ A crucial feature of this approach is that there are non-doxastic antecedents to belief that are sufficiently like belief to have contents that stand in interesting support relations to beliefs.

${ }^{20}$ If Fumerton $(1995,2013)$ can be classified as an evidentialist, he is an advocate of this approach. On his view, the rational support that we have for our non-inferentially justified beliefs involves acquaintance with certain things (facts, thoughts, and a correspondence relation between them) where the acquaintance relation is not intentional or representational. One reason to worry about lumping Fumerton in with the evidentialists is that his view implies that when we have non-inferential justification to believe $\mathrm{p}$, the justification derives from acquaintance with the fact that $\mathrm{p}$ (and 
representational content of any kind but would be something like a mark, clue, indication, or sign of the target states that could justify a belief about these target states only if the support is somehow made available to the thinker. We'll call this the 'awareness' view of support. It's important to distinguish these approaches because a lack of clarity about support can help to shield the weakness of the evidentialist view. Neither approach will give us an adequate account of non-inferential justification because there are clear cases of non-inferential knowledge without support as these views conceive of it.

\subsection{The Occupational View}

Some proponents of the non-occupational view would say that the possibility of perceptual knowledge provides no support for (P3). On this approach, the problem with $\mathrm{E}=\mathrm{K}$ is not with the idea that support needs to be understood in terms of propositions that we have in mind, but with the idea that the relevant propositions have to be believed to provide support. ${ }^{21}$ In the case of perceptual knowledge, the beliefs that constitute this knowledge would count as evidentially based by virtue of the fact that the subject's experiences have propositional contents that stand in the right kinds of rationalizing relations to the subject's doxastic attempts.

The success of this response rests on a few controversial assumptions. The first is that a subject might possess a propositionally specified reason without believing the proposition specified as the reason..$^{22}$ The second is that a subject's experience can have a representational content that we specify using that-clauses. ${ }^{23}$ While I think that both assumptions are false, we don't have to enter into these debates now. We can bracket the question as to whether the occupational model works for perceptual knowledge and take up the more pressing question, which is whether it can account for our intuitions about all cases of non-inferential knowledge. If not, the argument would rule out one

acquaintance with further things), so his view implies that we often have no evidence for believing $\mathrm{p}$ to be a fact distinct from the fact that $\mathrm{p}$.

${ }^{21}$ Versions of this idea can be found in Brueckner (2009), Dougherty (2011), McDowell (1994), Schellenberg (2011), and Schroeder (2011). Is this a view that Conee and Feldman defend? It is difficult to say. In some places they seem to think of evidence as the information that a thinker 'has to go on'. In other places, they seem to think that a subject's evidence is constituted by her experiences. This doesn't really tell us whether they think experiences have contents or whether their contents play an interesting epistemological role.

${ }_{22}$ Unger (1975) observed that propositionally specified attributions of reasons entail corresponding knowledge claims, so the linguistic data points decisively against nondoxastic accounts of the possession of propositionally specified reasons. While some would prefer to ignore the linguistic data, there are good philosophical reasons for being concerned about non-doxastic accounts of the possession of propositionally specified evidence. See the subsequent note. For a helpful discussion of the ontology of reasons generally, see Alvarez (2010).

${ }_{23}$ While many people now think that experiences have representational or propositional content, Brewer (2011) and Travis (2013) have made a convincing case against this idea. 
version of the Dependence Thesis even if the occupational view were right about perceptual justification.

There seem to be a number of problem cases for the occupational view's handling of non-inferential knowledge. We should look for the cases where it seems there is no sign that anything that could play the support role as the occupational view conceives of it is present. Consider, for example, the knowledge that you have that you are thinking about Agnes, the knowledge that Agnes has that there is a pain in her knee, the knowledge that Agnes has that she is making a pie or trying to chop the apples, the knowledge that Agnes has that her legs are crossed under the table, and the knowledge that Agnes has that it seems that the housing market is heating up again. In none of these cases does it seem that there is anything that plays the support role as understood by the occupational view. There is no state of mind that is distinct from both the target and the attempt that has a content that could rationally support the attempt in question..$^{24}$ We don't know about our own pains (e.g., their apparent locations, their intensity, that they are a pain rather than a tickle), say, because betwixt the intense sensation and the belief about it and its properties is a further state of mind that represents the properties of the pain. The same holds for the other cases of selfknowledge, too. We don't know that we're thinking about epistemology because in addition to the first-order attitudes in virtue of which we're thinking about epistemology there is some further set of propositional attitudes about these attitudes that support the higher-order belief that we're thinking about epistemology. ${ }^{25}$

One reason that these cases seem like trouble for the occupational view is that it seems implausible that there is something that has the right features to play the support role that is necessary for the justification of our attempts to get the targets right. There does not seem to be any representational state of mind that, say, represents Agnes as believing that it is raining that justifies her belief that this is what she believes. Why would the mind need this third representational state? The mind would need some way to classify first-order mental states as being a certain type of state (e.g., a belief, a desire, a hope, etc.) and as having a certain content and I see no reason to think that it could only get its work done and lead to knowledge if it took in some sort of input and then

${ }^{24}$ It is helpful to control for controversies about the nature of pain. Hyman (2003), for example, identifies them with modes of sensitive parts of our bodies. Tye (1995), however, insists that they are representational states of mind. The epistemology of the knowledge about our representational states of mind might look very different to the epistemology of states of the body or non-representational aspects of our mental lives. (The issue is further complicated by the fact that there might be no unified approach to pain that is adequate. See Corns (2014).)

${ }_{25}$ Having looked for evidentialist discussions of the justification we have for beliefs about our own thoughts and actions, it looks as if the evidentialists have confined their discussions to the justification of introspective beliefs about our own experiences. (See, for example, Feldman's discussion of the speckled hen in Conee and Feldman (2004).) In these discussions, it certainly looks as if the proposals dispense with any support that would be distinct from the target and the attempt. 
spit out some kind of output that had a representational content like the second-order belief that was distinct from the belief itself. If Agnes knows that she's thinking about Agatha, she does not settle this question correctly because there is, in addition to the thought, a representational state of mind that justifies her belief that represents her as thinking about Agatha..$^{26}$ This seems that this is all that is required to do justice to the phenomenology and all that is needed for higher-order knowledge of our own mental lives.

There are two ways to press the objection. First, if there is no non-doxastic representational state of mind distinct from the attempt and the target, the occupational view implies that these aren't cases of knowledge. Since these seem to be paradigmatic cases of knowledge, the occupational view seems to deliver the wrong verdicts. Second, even if, say, our best cognitive scientists agree that there are suitable non-doxastic states in each case, it's troubling that we don't believe that there are suitable non-doxastic states in these cases. By that I mean, our intuitions about such cases aren't triggered by the belief that such states are present because we don't assume that they are. We're either agnostic or believe that they're absent, but we still think that the relevant cases are cases of knowledge. If we don't believe that such states are present, but we think that these cases are paradigmatic cases of knowledge, the occupational view does not mesh with our intuitions. By our lights the thing that the view says is essential for justification isn't present, but we think justification is present.

\subsection{The Awareness View}

The problem with the occupational view is that it takes justification to depend upon the presence of representational states of mind that we don't have any reason to believe in. If such states don't exist, some of the epistemic assessments that we are most confident of would turn out to be false. Until we know that such states exist, we cannot rationally stand behind these assessments. Since it seems pretty clear that we know what we're thinking and doing and seem to have no real reason to question these assessments, the

${ }^{26}$ Kevin McCain raised an important question at this point. Suppose at $t$, Agnes believes that it is raining but isn't reflecting on this belief. Her attention is elsewhere. Suppose at $t^{\prime}$, however, she is reflecting on her belief. The differences might matter to the epistemology of self-knowledge. Couldn't the evidentialist say that the difference in what Agnes has justification to believe or is in a position to know is a difference that is due to a difference in evidence? Perhaps, but this is where matters get tricky. On the occupational view, the relevant difference-making mental state would be a representational state of mind distinct from the first-order target and the second-order attempt. I see no reason to think that the relevant shifts in attention are due to the onset or acquisition of such states or to think that the ability to acquire the self-knowledge that Agnes can have at $\mathrm{t}^{\prime}$ is itself due to the presence of such states rather than, say, a method, ability, or process that involves attention as part of its normal function. When it comes to the Cartesian self-verifying judgments (e.g. this thought is about such and such), it seems implausible that there is, in addition to this judgment, a distinct state of mind that represents the judgment in light of which we can work out that it is true. We use an infallible skill, method, or ability. 
best thing we can say about the occupational view is that it clashes with intuition. Happily, there is an alternative view, the awareness view.

The key difference between these views is that the awareness view doesn't take the support that is purported to determine whether our attempts at getting our targets right to involve any kind of content or representational state of mind. We are somehow able to access some things that play the support role by means of some nonrepresentational mode of awareness. ${ }^{27}$ One helpful case to consider by way of illustration might be the case in which various things are observed and we form a belief about some targets by means of inference to best explanation (e.g., we observe some crumbs, the hole in the wall, hear the squeaks, and infer that a mouse is present). The observables needn't be representational states of mind or have content to play the support role here. Perhaps we can construct a similar model for a wider range of beliefs, such as beliefs about the observable things in our environment where we take the evidential basis to be, say, aspects of a thinker's subjective mental life and model the support relation on something like inference to best explanation.

How far can we extend this model? Let's bracket concerns we might have about using this model to account for the justification of beliefs about the things we perceive in our surroundings because the interesting cases will be similar to those discussed above. The key difference between these models appears to be that neither the evidence possessed nor the possession of it requires a representational state of mind distinct from the attempt or the target. The view should thus avoid the objection to the occupational view (i.e., that it makes certain forms of non-inferential knowledge contingent upon the presence of states of mind we have no good reason to believe in).

Unfortunately, it is hard to have much confidence in this approach since it is hard to see how awareness that involves no representational element could help with the full range of cases. Consider the case of knowledge of our own beliefs. Thought contents are conceptual and they individuate our attitudes. How could a nonrepresentational mode of access to anything ground knowledge of states individuated by their conceptual contents? I don't see how the same kind of non-conceptual awareness that is involved in, say, the knowledge we have of the intensity of sensation could be something that grounds knowledge of the conceptual contents of our thoughts (e.g., that it grounds the knowledge that Agnes has when she knowingly reports that she's been thinking about economics, not poetry). If such awareness is not representational or intentional, it is properly reported and fully characterized in terms of extensional reports (i.e., those reports that allow for the substitution of co-referential expressions salva veritate). This kind of awareness that involves no exercise of conceptual capacities could not bring before the mind something non-representational that tells us that we believe as opposed to hope or tell us that our beliefs about, say,

${ }^{27}$ Fumerton (1995) defends something in the neighborhood of this approach because he thinks that we have non-inferential justification when we have awareness of a truthmaker, the thought that's true because of the truth-maker, and the truth-making relation between them. On his view, awareness is not conceptual or representational. 
water or Hesperus as opposed to $\mathrm{H} 2 \mathrm{O}$ or Phosphorus. If the goal is to determine whether you yourself have a belief that pertains to some target, a clue or piece of evidence that does not involve the same conceptual capacities exercised in that thought will be worthless. ${ }^{28}$

A proponent of this view might say that the discussion overlooks a view that somehow sits between the occupational and awareness view. The idea would be that simply being in some state of mind is enough to have evidence even if this state of mind isn't itself representational and doesn't have content and even if we don't have access or awareness to this state. This proposal might seem to avoid some problems, but it seems to face one significant problem of its own. Williamson's (2000) anti-luminosity argument shows that the mere fact that some mental state obtains or some such event occurs is not sufficient to ensure that a subject is in a position to know that it obtains. This means that when a subject is in a position to know that the state obtains, it is a special case and something has to distinguish this case from the case where the subject isn't in a position to know. The relevant difference maker will not be evidence the thinker possesses, not on the present understanding of what that could be. The difference maker could be an ability, process, method, but it would not be a tool that we take from the evidentialist kit.230

Once we see that some non-inferential knowledge is not evidentially based, we can see that the Path Principle is mistaken and why it is mistaken. We see that it is

${ }_{28}^{28}$ It's not just knowledge about states with conceptual content that are problematic for this view. See Anscombe's (1964) discussion of knowledge without clues in connection with our knowledge of the positions of our own limbs.

${ }^{29}$ Kevin McCain asked whether these are tools that the evidentialist can take on board or claim were already in their kit. I think not. The full range of abilities, capacities, skills, and methods will not supervene upon a thinker's evidence so at best they would figure in an account of doxastic justification by playing some role in basing a belief on the evidence. We have no reason to think that such things, however, operate on evidence in the full range of cases. Indeed, we have good reason to think that they will not, not if such things are modes of awareness that are not representational. Such modes of awareness would not come into contact with anything that would serve as the appropriate input into a process that could be counted on for determining what content some first-order attitude had precisely because it would not involve the exercise of the conceptual capacities necessary for grasping the content of this attitude.

${ }^{30}$ It is helpful to consider an extreme test case for the view, cases of what Burge (1988) calls 'basic self-knowledge'. In the case where a thinker knows that she is thinking (with this very thought) about water, the thinker's knowledge is itself the thought that the knowledge is about. The thinker can have this knowledge even if there was nothing antecedent to this thought or the subject's use of the infallible method for determining that she has this thought that could be the thinker's evidence for this belief. The Path Principle would imply that because there was nothing prior to the thinking of the thought that could have provided evidential support for the relevant belief that the relevant belief could not have been justified. The belief is justified and constitutes knowledge because of the use of a good method or process, not because of a response to independently possessed evidence that supports belief. 
mistaken because the principle implies that when a thinker has no evidence that supports believing $\mathrm{p}$ or believing $\sim \mathrm{p}$ the thinker could not have justification to believe $\mathrm{p}$ and fail to have justification to believe $\sim p$. This implication runs counter to intuitive verdicts about cases where we think, pre-reflectively, that a thinker knows whether $p$ but does not have anything that could play the roles of evidence as understood by the two approaches discussed above. The problem with the principle is that it overlooks the possibility that evidential support is but one way amongst many for a belief to attain positive epistemic status. In the case of non-inferential knowledge (or, more cautiously, some such cases), the crucial factors that determine whether there is justification to believe will not be evidence, but some process, mechanism, method or ability that doesn't simply operate on or process evidence that yields true beliefs without the need for supporting evidence.

\section{The Sufficiency Thesis}

Our discussion has focused on non-inferential justification and knowledge. Readers might wonder whether evidentialism might be right about inferential belief. While we might allow that there are some beliefs that can be justified without the need of supporting evidence, we might think that those that do need supporting evidence to be justified would be those that show that some the Path Principle, suitably restricted, might be correct.

There is an argument that shows that the Path Principle fails even for the inferentially justified beliefs that need evidential support to be justified:

P1. A belief is justified iff it conforms to the norms that govern belief. ${ }^{3}$

P2. A thinker's belief conforms to these norms iff it constitutes knowledge. ${ }^{32}$

C1. A thinker's belief is justified iff it constitutes knowledge.

P3. Two thinkers with precisely the same evidence for their

belief in $\mathrm{p}$ can differ in that only one of them was in a position to know $\mathrm{p}$.

C2. Thus, two thinkers with precisely the same evidence can differ in that only one of them has a justification to believe $p$.

The guiding idea is that justification is a normative notion and that the presence of it turns on whether the thinker's beliefs conform to the norm that governs belief. This norm is the knowledge norm, or so I assume. Because we all agree that being in a position to know $\mathrm{p}$ would be necessary and sufficient for being in a position to conform

${ }^{31}$ The norms are formulated in terms of what the agent should not believe. If the thinker violates no norm, it is not the case that the agent should not believe what she does. In other words, the belief is permitted, justified, etc. For a discussion of this normative conception of justification, see Littlejohn (2012).

${ }^{32}$ For defenses of the knowledge norm, see Littlejohn (forthcoming b), Steglich-Peterson (2013), Sutton (2007), and Williamson (2000). 
to the fundamental epistemic norm if (P1) is true and agree that being in a position to know does not supervene upon a thinker's evidence, we get our desired result. A thinker's evidence does not wholly determine whether there is a path from the thinker's evidence at any particular time that wholly determines whether the inferential beliefs she formed on the basis of that evidence. If the thinker draws an inference and therein comes to know, the inferential belief couldn't fail to be justified. If a thinker in the same evidential situation draws that inference and comes to believe without knowing, she couldn't have a justified belief. This kind of luck is unavoidable.

I don't offer this argument to persuade evidentialists. It is the opening gambit. Just as the Path Principle does not mesh with live options in debates about the nature of evidence and its possession, it does not mesh with live options in debates about the identity of the norms that govern belief. Because of this, it's fair to press the evidentialist for a defense of the Path Principle. I should note at this point that I have never seen any argument for the Sufficiency Thesis in the literature. In conversations with those sympathetic to evidentialism, I've been told that while there is no such argument in the literature, the strongest case for the core commitments of the view is indirect. The idea is that the evidentialist will try to show that their view does the best job accounting for cases and vindicating intuitions. We've already seen some reason to think that the view fails to do this since it struggles to handle some cases of noninferential knowledge. In this section we shall also see that it clashes with some intuitions about rational belief.

It is clear that the Sufficiency Thesis would be false if (P1) and (P2) were correct. If the justification of belief depended upon whether it constituted knowledge, justification would not supervene upon the evidence because facts about what a thinker is in a position to know do not supervene upon the thinker's evidence. If we combine (P2) with the Path Principle, we get the result that there is no adequate path of evidential support that would take a thinker to $p$ unless every thinker with just her evidence would be in a position to know that $\mathrm{p}$. For many things that we know, no such paths exist. Cases of inductive knowledge come to mind here. Even if you accept $E=K$, for example, you'd have to acknowledge that a complete description of a subject's evidential paths wouldn't determine whether the thinker would have justification to believe $p$ because the truth of the conclusion of an inductive inference does not supervene upon a thinker's present knowledge.

This might convince some people that they ought to reject (P2). It might seem obvious to some people that a complete description of the thinker's evidence must determine whether it would be appropriate to use it by drawing an inference from it or basing a belief on it. If you think that this is the right thing to say, you might replace (P2) with something that would allow for justification without knowledge:

(P2') P2. A thinker's belief conforms to these norms iff it is based on sufficient evidence.

If we substitute this evidentialist thesis for (P2) in the argument, it's clear that the argument's conclusion cannot be reached. While I won't argue here for the conclusion 
that (P2) is preferable, we will see that (P2') suffers from the same kind of problem that (P2) is alleged to. Given some plausible assumptions about what rationality requires from us, there will be situations analogous to the situations taken to be problematic for (P2): pairs of thinkers who have the same evidential support for their respective beliefs can differ in that only one thinker has sufficient justification for her beliefs.

Let's start by considering a putative rational requirement that many of us take to be intuitively compelling, the requirement that says that it's irrational to fail to $V$ when you believe that you ought to V. This requirement, which is known as the 'Enkratic Requirement', states that it is irrational to be akratic and it seems that on its best formulation it is a wide-scope requirement (i.e., one that says that rationality prohibits a certain combination). When formulated as a wide-scope requirement, we don't face problems with bootstrapping or irrational beliefs putting rational pressure on a thinker to $\mathrm{V}$. While we formulate this as a wide-scope requirement, Titelbaum has shown us how to derive a narrow-scope requirement from it, one that says that whenever rationality prohibits V-ing, it is not rational to believe that V-ing is required. The upshot of this is that rationality prohibits a certain kind of mistaken normative belief, one that represents V-ing as required when V-ing is prohibited. According to the Fixed-Point Thesis, this putative rational requirement is a genuine one.

The Fixed-Point Thesis is a surprising consequence of the Enkratic Requirement. ${ }^{33}$ If the Fixed-Point Thesis is correct, we can use it to attack the Sufficiency Thesis. First, let's suppose that Jermaine is in the good case and he knows that he ought to V. He thus has sufficient evidence to believe that he ought to V. (Why think that? Remember that we're assuming that Jermaine's belief is justified if it constitutes knowledge and that a thinker cannot fail to have adequate evidence if the thinker has a justified belief. ${ }^{34}$ ) On the evidentialist view, there must be something that plays the evidence role that provides adequate support for Jermaine's belief. ${ }^{35}$

Next, let's stipulate that Jack has evidence that provides the same type of support for his belief that he ought to $V^{\prime}$. Because of this and because Jermaine's belief is justified, the Sufficiency Thesis tells us that Jack should have adequate evidence and justification to believe that he ought to $\mathrm{V}^{\prime}$. However, we should be able to stipulate that

${ }^{33}$ Titelbaum (2015a) shows us how to derive the Fixed-Point Thesis from the Enkratic Requirement. The proof is not particularly complicated and the assumptions needed for the derivation are not particularly controversial. In Littlejohn (2012), I argued that something like the Fixed-Point Thesis supported a form of externalism about justification that was incompatible with evidentialism and argued that we needed this kind of externalism to understand how there could be categorical requirements that applied to all rational agents.

${ }^{34}$ In this context, a thinker can have adequate evidence even if there is nothing in her body of evidence that supports the target proposition if, say, the proposition is one that the thinker can justifiably believe without evidence.

${ }^{35}$ We don't have to worry about what this evidence might be. It could be seemings or appearances, propositions that are the contents of the thinker's mental states, facts that the thinker knows, or facts about the thinker's mental states. 
Jack ought not $\mathrm{V}^{\prime}$. The Fixed-Point Thesis implies that Jack's belief is not justified. Thus, there is a clash between the Sufficiency Thesis and the Fixed-Point Thesis. In turn, there is a clash between evidentialism and the Enkratic Requirement.

The Fixed-Point Thesis implies that Jack cannot rationally believe that he ought to $\mathrm{V}^{\prime}$. If it is not rational for him to believe that he ought to $\mathrm{V}^{\prime}$ even though he has evidence that provides the same type of support for his normative beliefs as Jermaine's evidence provides, we should reject the Sufficiency Thesis. Although the contents of their normative beliefs differ and different things are included in their respective bodies of evidence, the same type of support relations hold between their respective normative beliefs and their evidence. If such relations wholly determined the justificatory standing of Jermaine's beliefs, they should ensure that Jack's beliefs were justified, too. They do not do that. Jack's normative belief is not justified. Thus, there is something further that matters to the justification of normative belief.

Notice that the argument is perfectly general. In arguing against the Sufficiency Thesis, we only assumed that a kind of fallible support relation is sufficient for justification and then pointed out that this relation should hold in the relevant good case/bad case pair. We didn't assume that sufficiency should be understood in terms of strength, high probability, or anything of the sort. Whatever support relation helps to make the good case good might be present without preventing things from going bad in the bad case and leading our thinker astray. For a special class of targets, it turns out that a certain kind of error is sufficient to ensure that the failed attempt is a rational failure, not some mere mistake. Since irrationally held beliefs are not justified, we have our counterexample to the Sufficiency Thesis: if evidential support were sufficient for justification, Jack's beliefs and Jermaine's beliefs would have the same status.

The evidentialist might consider one of two lines of response. First, they might try to show that evidentialism is actually compatible with the Enkratic Requirement. ${ }^{36}$ It seems that they are incompatible because it seems, crudely put, that whatever target we attempt to get right, it's always possible for the support we have to lead us astray. Suppose, for example, that you take the support that Agnes has for believing that she ought to $\mathrm{V}$ to be an intuition or a seeming with a certain content: that she ought to V. If this, given Jermaine's total evidence, makes it the case that she can justifiably believe that she ought to $\mathrm{V}$, it should be possible for someone like Jack to have a body of evidence that includes the seeming that he ought to $\mathrm{V}^{\prime}$ and be suitably modified so that the same support relations hold between Jack's supporting evidence and his belief. Thus, we'd expect the evidentialist to say that their beliefs have to have the same justificatory status. This assumption can be challenged. Some might say that there is some sort of necessary connection between the normative truths and what a body of evidence can support.

${ }^{36}$ I agree with Coates (2012), Field (forthcoming), and Lasonen-Aarnio (MS) that evidentialism is incompatible with the Enkratic Requirement. See Littlejohn (forthcoming) for a defense of the requirement. 
One way to understand the proposal is by thinking about an analogy with logical truths. ${ }^{37}$ Whatever evidence a thinker has, it's a consequence of the probability-raising conception of evidential support that a thinker has maximal support for the truths of logic. This is not because every thinker has some premise or set of premises that could figure in her reasoning that could lead her to reason well to the conclusion that these truths are true, however. Perhaps something similar could be said about normative truths. The idea is not that every thinker has a premise or set of premises that could figure in good reasoning that would lead them to see the light; rather, the idea is that every body of evidence (including one free of any pieces of evidence) provides maximal support for some truths (e.g., logical truths and (perhaps) normative truths).

As interesting as this proposal is, I don't think that it accounts for the relevant data. This idea that we all have maximal evidential support for truths about the requirements of rationality is not plausible if we're talking about truths about particular cases where the reasoning that leads us to conclusions about what rationality requires rests on some empirical assumptions. When it comes to particular judgments about particular cases, however, this loses plausibility because such judgments rest on assumptions about the particular case that often can only be known through observation. (Contrast the judgment that we should be conciliatory in a case of peer disagreement and the judgment that I should be conciliatory when Agnes tells me that I've miscalculated the tip.) The important point is that our intuitions about rationality extend to particular cases where we think it would be irrational for someone to fail to $\mathrm{V}$ when they've judged on the basis of a mix of apriori and empirical considerations that they ought to $V$. Thus, a complete explanation of the relevant intuitions about rational combinations of mental states needs tools that the evidentialists don't have.

The evidentialist could, of course, just deny the Fixed-Point Thesis, but they'd have to deny the Enkratic Requirement, too. That comes with the obvious cost that we'd be rejecting a widely shared intuition about rationality (i.e., that we should avoid the incoherent clashes that constitute epistemic akrasia) to preserve a principle about the relationship between evidence and justification that we have no good reason to accept. If we don't have evidence for the Sufficiency Thesis it wouldn't be in keeping with the spirit of the view if we cleaved to it when faced with arguments against it.

Discussion of the Enkratic Requirement reveals something important about the tempting idea that a complete description of a thinker's evidential support should wholly determine whether they have justification to believe a proposition Because (P2) conflicts with this idea, it is tempting to reject it and replace it with an evidentialist view

${ }^{37}$ See Titelbaum (2015b) for some discussion of the analogy. Some authors (e.g., Smithies (2012), Ichikawa and Jarvis (2013)) seem to think that we have a special kind of evidential support or justification for believing the logical truths as well as the truths about the requirements of rationality. (It is unclear whether these authors distinguish propositional justification from adequate evidential support.) In Dutant and Littlejohn (forthcoming), we present a number of problems for views on which facts about the requirements of rationality satisfy some kind of epistemic constraint. 
that supports (P2'). If the Enkratic Requirement is correct and there are fixed-points in Titelbaum's sense, we have to abandon the idea that the type of evidential support we have for believing some normative propositions wholly settles whether there is justification to believe them. In these special cases (at least), certain kinds of mistakes cannot be rationally made whatever support we have for believing the mistaken proposition. The requirement shows that a complete description of a thinker's evidence support does not wholly determine whether they have justification to believe. The precise nature of that type of support does not matter. The point generalizes to every notion of support that can be characterized in non-normative terms and allows for a non-skeptical view on which it's possible to know and justifiably believe some things about the requirements of rationality.

Notice, too, that the problems that these fixed-points generate show something interesting about the supervenience of justification upon evidence. Suppose the relevant fixed-points are necessary truths about the requirements of rationality, such as requirements about how we should respond to disagreement, what we should think about lottery cases, or general requirements concerning logical consistency. These truths will supervene upon any body of evidence because they are necessary truths. Thus, we do not need to point to conditions that fail to supervene upon a thinker's evidence to show that the Sufficiency Thesis is false. Even if justification did supervene upon a thinker's evidence, the type of evidential support relations that hold between the thinker's beliefs and the propositions they believe would still not determine whether the thinker had adequate justification to believe. Thus, while I think that justification does not supervene upon a thinker's evidence and does not supervene upon a thinker's nonfactive mental states, we can construct counterexamples to the Sufficiency Thesis without begging the question against those who insist that these theses are true.

\section{Conclusion}

I have pointed to two problems with the Path Principle. It's possible to acquire knowledge and justified belief without supporting evidence. Thus, the absence of a path of evidential support is itself not a decisive reason to think that a thinker could not have a justified belief about some matter. In some cases of non-inferential knowledge, the methods by which our beliefs are formed are methods by which we acquire knowledge and thereby acquire evidence. The methods do not themselves need to operate on anything that we would recognize as evidence. It is also possible for thinkers to have beliefs that differ in justificatory status when their respective beliefs receive the same type of evidential support. Thus, the type of support relations that hold between a body of evidence and a proposition does not completely settle whether a thinker has justification to believe the proposition just as this evidence and the support it provides does not completely settle whether a thinker is in a position to know the proposition.

Once we reject the Dependence Thesis and the Sufficiency Thesis, we do not need a further argument against the Determination Thesis. This seems like a good place to stop. 


\section{References}

Alvarez, Maria. 2010. Kinds of Reasons. Oxford University Press.

Anscombe, G.E.M. 1962. On Sensations of Position. Analysis 22: 55-8.

Brueckner, Anthony. 2009. $\mathrm{E}=\mathrm{K}$ and Perceptual Knowledge. In P. Greenough and D. Pritchard (eds.), Williamson on Knowledge. Oxford University Press.

Burge, Tyler. 1988. Individualism and Self-Knowledge. Journal of Philosophy 85: 649-63.

Coates, Allen. 2012. Rational Epistemic Akrasia. American Philosophical Quarterly 49: $113-24$.

Comesana, Juan. 2005. We Are (Almost) All Externalists Now. Philosophical Perspectives 19: 59-76.

Conee, Earl and Richard Feldman. 2004. Evidentialism. Oxford University Press.

Conee, Earl and Richard Feldman. 2008. Evidence. In Q. Smith (ed.), Epistemology: New Essays. Oxford University Press.

Corns, Jennifer. 2014. The Inadequacy of Unitary Characterizations of Pain. Philosophical Studies 169: 355-78.

Dougherty, Trent. 2011. In Defense of Propositionalism about Evidence. In T. Dougherty (ed.), Evidentialism and Its Discontents. Oxford University Press.

Dutant, Julien and Clayton Littlejohn. Forthcoming. Just Do It? When To Do What You Judge You Ought To Do. Synthese.

Gibbons, John. 2014. The Norm of Belief. Oxford University Press.

Fantl, Jeremy and Matt McGrath. 2009. Knowledge in an Uncertain World. Oxford University Press.

Field, Claire. Forthcoming. It's OK to Make Mistakes: Against the Fixed Point Thesis. Episteme.

Fumerton, Richard. 1995. Metaepistemology and Skepticism. Rowman and Littlefield.

Fumerton, Richard. 2013. Knowledge, Thought, and the Case for Dualism. Cambridge University Press.

Hyman, John. 2003. Pains and Places. Philosophy 78: 5-24.

Ichikawa, Jonathan and Ben Jarvis. 2013. The Rules of Thought. Oxford University Press.

Lasonen-Aarnio, Maria. MS. Enkrasia or Evidentialism: Learning to Love Mismatch.

Littlejohn, Clayton. 2012. Justification and the Truth-Connection. Cambridge University Press.

Littlejohn, Clayton. Forthcoming. Stop Making Sense? On A Puzzle about Rationality. Philosophy and Phenomenological Research.

Littlejohn, Clayton. Forthcoming b. How and Why Knowledge is First How and Why Knowledge is First. Forthcoming in A. Carter, E. Gordon, and B. Jarvis (ed.), Knowledge-First Epistemology. Oxford University Press.

McCain, Kevin. 2014. Evidentialism and Epistemic Justification. Routledge.

McDowell, John. 1994. Mind and World. Harvard University Press.

Mitova, Veli. Forthcoming. Truthy Psychologism about Evidence. Philosophical Studies. 
Neta, Ram. 2008. What Evidence Do You Have? British Journal for the Philosophy of Science 59: 89-119.

Schellenberg, Susanna. 2011. Perceptual Content Defended. Nous 45: 714-50.

Schroeder, Mark. 2011. What Does it Take to 'Have' a Reason? In A. Reisner and A. Steglich-Petersen (ed.), Reasons for Belief. Cambridge University Press.

Smithies, Declan. 2012. Moore's Paradox and the Accessibility of Justification. Philosophy and Phenomenological Research 85: 273-300.

Steglich-Petersen, Asbjorn. 2013. Truth as the Aim of Justification. In T. Chan (ed.), The Aim of Belief. Oxford University Press.

Sutton, Jonathan. 2007. Without Justification. MIT University Press.

Titelbaum, Michael. 2015a. How to Derive a Narrow-Scope Requirement from WideScope Requirements. Philosophical Studies 172: 535-42.

Titelbaum, Michael. 2015b. Rationality's Fixed Point (Or: In Defense of Right Reason). In J. Hawthorne and T. Gendler (ed.), Oxford Studies in Epistemology. Oxford University Press.

Travis, Charles. 2013. Perception: Essays after Frege. Oxford University Press.

Tye, Michael. A Representational Theory of Pains and their Phenomenal Character. Philosophical Perspectives. 9: 223-39.

Unger, Peter. 1975. Ignorance. Oxford University Press.

Williamson, Timothy. 2000. Knowledge and its Limits. Oxford University Press. 